\title{
The happiness and income correlation
} in Canada

\section{Anthony Jehn}

Department of Sociology, College of Social and Applied Human Sciences, University of Guelph, Guelph, ON Canada. Faculty supervisor: Dr. David Walters. For correspondence, please email: ajehn@uoguelph.ca.

\section{Abstract}

Does having more income make you happier? Current literature shows varied results regarding the correlation between perceived happiness and income. This article uses data from Statistics Canada's General Social Survey (GSS) in order to examine the relationship between income and perceived happiness in a Canadian context. Findings indicate that annual income does not seem to be correlated with perceived happiness in Canada, thus challenging the age-old adage that money can buy happiness.

Keywords: happiness; income; correlation; Statistics Canada General Social Survey (GSS)

\section{Introduction}

Individuals often associate increased income with increased happiness. This is a common belief because of the greater individual utility and freedom that income affords. A variety of research has demonstrated direct links between income and increased happiness. A higher income improves an individual's sense of utility because money can be exchanged for a vast variety of goods (Boyce et al. 2010). By obtaining desired goods, an individual is likely to feel as if they are fulfilling their wants or needs. Therefore, the higher the amount of income an individual has at their disposal, the higher their sense of fulfillment and well-being (Boyce et al. 2010). When examining the correlation between income and happiness from a variety of sources, the results are often positive and strong (Hsieh 2011). When an individual does not have an income, they are not only less happy, but can actually experience misery as a result (Hsieh 2011).

In addition to the amount of income an individual earns, their level of happiness is also attributable to their perception of that income. It has been shown that individuals are likely to consider how their income ranks against that of other people. In addition to the actual monetary value of their income, an individual is also likely to examine where they fall into an income distribution based on societal norms (Boyce et al. 2010). In this process, they will often compare themselves to people that they know. For example, an individual could compare how their income ranks with their coworkers, their neighbours, or with their friends (Hsieh 2011). In this scenario, the individual's perception of happiness is a direct result of their income; however, it is based on what that income means from a sociological perspective, as opposed to the level of utility that it offers.

An individual's perception of happiness can also be affected by the income that they believe they should be earning. Having high personal expectations can be very motivating; however, it can also result in diminished perceptions of happiness. An individual can experience temporary happiness when they first receive an income, but this may not be a long-term benefit (McBride 2010). If an individual had previously earned a certain income, then they may not be happy with a future income that does not match their previous earnings (McBride 2010). Alternatively, an improvement of income within an individual's comparison group may also diminish happiness with one's own income over time (McBride 2010).

Another factor that could affect the income and happiness correlation is where an individual chooses to focus their energy. The energy an individual puts towards earning money can be examined and interpreted as an amount of time spent. A focus on money promotes an emphasis on maximizing personal economic gains, which may result in increased time spent working and less time spent pursuing activities that would normally provide happiness (DeVoe and House 2012). The concept of an hourly wage further promotes an individual's interpretation that time is money (DeVoe and House 2012). Normally, time would be considered ambiguous because an individual has the freedom to spend it in a multitude of ways. However, when an individual begins to focus heavily on economic gain, they are left with less time to explore other facets of life and may begin to see each hour as a loss of the compensation they could possibly be earning (DeVoe and House 2012).

Focusing on economic gains will likely increase an individual's income; however, it will not necessarily increase their perceived happiness. Time spent on other activities lack a direct connection to a measurable amount of economic gain; thus, the individual will become less inclined to enjoy 
this time (DeVoe and House 2012). They may begin to distinguish between spending time on money and wasting their time (DeVoe and House 2012).

Table 1. Summary of descriptive statistics for the variables in this study.

\begin{tabular}{|c|c|}
\hline Variable & Mean/Proportion \\
\hline $\begin{array}{l}\text { Happiness } \\
(n=997)\end{array}$ & $\begin{array}{c}\text { Very Happy } \\
\text { (Mean Score=1.57) }\end{array}$ \\
\hline $\begin{array}{l}\text { Income } \\
(n=788)\end{array}$ & $\begin{array}{c}\$ 20,000-\$ 29,999 \\
\text { (Mean Score }=6.24 \text { ) }\end{array}$ \\
\hline $\begin{array}{c}\text { Age } \\
(n=1000)\end{array}$ & $\begin{array}{c}40-44 \\
\text { (Mean Score }=7.42 \text { ) }\end{array}$ \\
\hline
\end{tabular}

For example, individuals who are focused on economic gains are less likely to help others in need (e.g., by volunteering or donating to charity) or to spend time with their families, activities that would generally be correlated with an increase in perceived happiness (Mogilner 2010).

More recent evidence suggests that increased income is not associated with increased happiness when more time is spent working, or may even lead to decreased happiness (Becchetti et al. 2011). Studies have shown that the amount of time spent working has increased in the United States (Mogilner 2010). This would provide higher incomes and personal wealth; however, reported levels of perceived happiness have largely remained unaffected (Mogilner 2010). Major economic growth in China does not appear to have made significant improvements to the population's satisfaction levels; in fact, the exact opposite has occurred, given that the number of people who consider themselves satisfied is decreasing and the number of people who consider themselves dissatisfied is increasing (Becchetti et al. 2011). In Europe, a decrease in the amount of time spent working has led to an increase in the population's happiness levels (Mogilner 2010). Thus, it appears that when more time is spent working, less time is spent pursuing other activities that are more enjoyable and may lead to greater perceived happiness.

Although it is easy to see how income and happiness should be correlated, this relationship should be interpreted with caution. With an increased income, an individual will have a higher level of utility and freedom to obtain what they want and need; however, too strong a focus on economic gain may prevent them from enjoying their earnings. Continuously comparing one's earnings to those of others and having unrealistically high personal expectations can also lead to diminished happiness. Thus, the purpose of this study is to determine if a correlation exists between happiness and perceived income for Canadian residents, using data from Statistics Canada's General Social Survey.

\section{Methods}

The data utilized in this study were obtained from Statistics Canada's General Social Survey (GSS) - Social Engagement Cycle 17. This survey was conducted by computer-assisted telephone interviews and had a response rate of $78 \%$. The data obtained from this survey were weighted by Statistics Canada to the non-institutionalized population aged 18 years and over in ten provinces.

The analysis in this article is based on 1,000 randomly selected respondents from the original survey. The variables used were the annual income of respondents and their perceived happiness. Both variables were considered quantitative due to the use of ordinal answer schemes. Happiness was coded on a Likert scale ranging from (1) "very happy" to (4) "very unhappy." Income was coded on a reverse-coded ordinal scale with 1 representing no income and 12 representing the highest income. Missing data, including all of the non-contributive answers, were removed from the analysis. A frequency analysis was conducted to determine the mean value of both variables. Moreover, since both variables were quantitative, a bivariate correlation was used to determine levels of significance.

\section{Results and Discussion}

Table 1 demonstrates the results of a frequency analysis for the variables considered in this study. The mean perceived happiness score was 1.57, indicating that on average, respondents were between "very happy" and "somewhat happy." The mean income score was 6.24, indicating an average yearly income in the range of $\$ 20,000$ $\$ 29,999$. These results show that the average respondent had a fairly high level of perceived happiness while having a fairly low annual income. The mean age of study participants was $40-44$.

A correlation analysis between perceived happiness and income showed a very weak negative correlation coefficient of -0.017 , indicating no statistically significant correlation between the two variables. Given that mean annual income was low and mean perceived happiness was high, it is probable that factors other than income influenced the perceived happiness of the respondents in the study.

Current literature shows varied results regarding the correlation between perceived happiness and income. Some studies suggest that income has a positive effect on happiness (Hsieh 2011). As discussed previously, this could be a result of the increased opportunities that higher income affords individuals, or the satisfaction of having a higher income than the other individuals in one's comparison group. However, other studies suggest possible downsides to higher income, including an inability to enjoy positive experiences due to a heightened focus on economic gain and thus, more hours spent working. These studies also indicate that income is not necessarily an accurate predictor of perceived happiness (DeVoe and House 2012; Mogilner 2010). The results of the current study favour the latter results.

This study's finding that perceived happiness is not significantly correlated with annual income implies that other factors are likely to be more significant predictors of happiness. For example, the respondents in this study might have spent more time engaging in activities outside of work 
that they considered fulfilling; in addition, they may have also been less concerned with how their income compared to others in their social group (Mogilner 2010).

Limitations of the present study are that only the correlation between perceived happiness and income was assessed; thus, the study was unable to determine exactly what factors might have contributed to the high levels of perceived happiness found among the respondents. In addition, external factors such as education, sex, and relationship status may have influenced the way in which a respondent perceived their income and therefore its impact on their happiness (Becchetti et al. 2011). Further research conducted should consider these variables. Despite these limitations, the study did shed light on what might be a common misconstrued belief. People do not need to have high levels of income in order to enjoy their life experiences. Taking the time to enjoy life and participate in activities that are fulfilling can help an individual remain satisfied and happy with their life.

\section{References}

Becchetti L, Corrado L, Rossetti F. 2011. The heterogenous effects of income changes on happiness. Social Indicators Research. 104(3): 387-406.

Boyce CJ, Brown G, Moore S. 2010. Money and happiness: rank of income, not income, affects life satisfaction. Psychological Science. 21(4): 471-475.

Devoe SE, House J. 2012. Time, money, and happiness: how does putting a price on time affect our ability to smell the roses? Journal Of Economic Behaviour \& Organization. 48(2): 466-474.

Hsieh, CM. 2011. Money and happiness: does age make a difference? Aging and Society. 31(8): 1289-1306.

McBride M. 2010. Money, happiness, and aspirations: an experimental study. Journal Of Economic Behaviour \& Organization. 74(3): 262-276.

Mogilner C. 2010. The pursuit of happiness: time, money, and social connection. Psycholgical Science. 21(9): 1348-1354. 


\section{Supplementary Information}

Table 1. Age group of the study respondents.

\begin{tabular}{|c|c|c|c|c|c|}
\hline & Age Group & Frequency & Percent & Valid Percent & Cumulative Percent \\
\hline \multirow{16}{*}{ Valid } & $15-17$ & 45 & 4.5 & 4.5 & 4.5 \\
\hline & $18-19$ & 31 & 3.1 & 3.1 & 7.6 \\
\hline & $20-24$ & 90 & 9.0 & 9.0 & 16.7 \\
\hline & $25-29$ & 80 & 8.0 & 8.0 & 24.7 \\
\hline & $30-34$ & 89 & 8.9 & 8.9 & 33.6 \\
\hline & $35-39$ & 97 & 9.7 & 9.7 & 43.3 \\
\hline & $40-44$ & 104 & 10.4 & 10.4 & 53.7 \\
\hline & $45-49$ & 100 & 10.0 & 10.0 & 63.7 \\
\hline & $50-54$ & 92 & 9.2 & 9.2 & 72.9 \\
\hline & $55-59$ & 57 & 5.7 & 5.7 & 78.5 \\
\hline & $60-64$ & 46 & 4.6 & 4.6 & 83.1 \\
\hline & $65-69$ & 35 & 3.5 & 3.5 & 86.6 \\
\hline & $70-74$ & 57 & 5.7 & 5.7 & 92.3 \\
\hline & $75-79$ & 43 & 4.3 & 4.3 & 96.6 \\
\hline & 80 and older & 34 & 3.4 & 3.4 & 100.0 \\
\hline & Total & 1000 & 100.0 & 100.0 & \\
\hline
\end{tabular}

Table 2. Perceived happiness level of the study respondents.

\begin{tabular}{|c|c|c|c|c|c|}
\hline \multicolumn{2}{|c|}{ Presently, would you describe yourself as: } & Frequency & Percent & Valid Percent & Cumulative Percent \\
\hline \multirow{6}{*}{ Valid } & very happy & 493 & 49.3 & 49.5 & 49.5 \\
\hline & somewhat happy & 449 & 44.9 & 45.1 & 94.5 \\
\hline & somewhat unhappy & 45 & 4.5 & 4.5 & 99.0 \\
\hline & very unhappy & 5 & .5 & .5 & 99.5 \\
\hline & no opinion & 5 & .5 & .5 & 100.0 \\
\hline & Total & 997 & 99.7 & 100.0 & \\
\hline Missing & not stated & 3 & .3 & & \\
\hline Total & & 1000 & 100.0 & & \\
\hline
\end{tabular}


Table 3. Annual personal income of the study respondents.

\begin{tabular}{|c|c|c|c|c|c|}
\hline & Annual Personal Income & Frequency & Percent & Valid Percent & Cumulative Percent \\
\hline & No Income & 46 & 4.6 & 5.8 & 5.8 \\
\hline & Less than $\$ 5,000$ & 36 & 3.6 & 4.6 & 10.5 \\
\hline & $\$ 5,000$ to $\$ 9,999$ & 65 & 6.5 & 8.3 & 18.8 \\
\hline & $\$ 10,000$ to $\$ 14,999$ & 80 & 8.0 & 10.1 & 28.9 \\
\hline & $\$ 15,000$ to $\$ 19,999$ & 64 & 6.4 & 8.1 & 37.0 \\
\hline & $\$ 20,000$ to $\$ 29,999$ & 147 & 14.7 & 18.7 & 55.7 \\
\hline Valid & $\$ 30,000$ to $\$ 39,999$ & 105 & 10.5 & 13.3 & 69.0 \\
\hline & $\$ 40,000$ to $\$ 49,999$ & 75 & 7.5 & 9.5 & 78.4 \\
\hline & $\$ 50,000$ to $\$ 59,999$ & 49 & 4.9 & 6.2 & 84.6 \\
\hline & $\$ 60,000$ to $\$ 79,999$ & 56 & 5.6 & 7.1 & 91.7 \\
\hline & $\$ 80,000$ to $\$ 99,999$ & 35 & 3.5 & 4.5 & 96.1 \\
\hline & $\$ 100,000$ or more & 30 & 3.0 & 3.9 & 100.0 \\
\hline & Total & 788 & 78.8 & 100.0 & \\
\hline & not stated & 109 & 10.9 & & \\
\hline Missing & don't know & 102 & 10.2 & & \\
\hline & Total & 212 & 21.2 & & \\
\hline Total & & 1000 & 100.0 & & \\
\hline
\end{tabular}

